\title{
BMJ Open Impact of first and second eye cataract surgery on physical activity: a prospective study
}

\author{
Lynn B Meuleners, Ying Ru Feng, Michelle Fraser, Kate Brameld, ${ }^{\circledR}$ Kyle Chow
}

To cite: Meuleners LB, Feng YR, Fraser M, et al. Impact of first and second eye cataract surgery on physical activity: a prospective study. BMJ Open 2019;9:e024491. doi:10.1136/ bmjopen-2018-024491

- Prepublication history for this paper is available online. To view these files, please visit the journal online (http://dx.doi. org/10.1136/bmjopen-2018024491).

Received 29 May 2018 Revised 8 0ctober 2018 Accepted 23 November 2018

Check for updates

(C) Author(s) (or their employer(s)) 2019. Re-use permitted under CC BY-NC. No commercial re-use. See rights and permissions. Published by BMJ.

Curtin-Monash Accident Research Centre, Curtin University, Perth, Western Australia, Australia

Correspondence to Dr Lynn B Meuleners; Lynn.Meuleners@uwa.edu.au

\section{ABSTRACT}

Objectives To investigate the impact of first eye and second eye cataract surgery on the level of physical activity undertaken by older adults with bilateral cataract. Design Prospective cohort study.

Setting Three public ophthalmology clinics in Western Australia.

Participants Fifty-five older adults with bilateral cataract aged 55+ years, awaiting first eye cataract surgery. Outcome measures The primary outcome measure was participation in moderate leisure-time physical activity. The secondary outcomes were participation in walking, gardening and vigorous leisure-time physical activity. Participants completed a researcher-administered questionnaire, containing the Active Australia Survey and visual tests before first eye cataract surgery, after first eye surgery and after second eye surgery. A Generalised Estimating Equation linear regression model was undertaken to analyse the change in moderate leisuretime physical activity participation before first eye surgery, after first eye surgery and after second eye surgery, after accounting for relevant confounders.

Results Participants spent significantly less time per week (20 min) on moderate leisure-time physical activity before first eye cataract surgery compared with after first eye surgery $(p=0.04)$ after accounting for confounders. After second eye cataract surgery, participants spent significantly more time per week (32 min) on moderate physical activity compared with after first eye surgery $(p=0.02)$. There were no significant changes in walking, gardening and vigorous physical activity throughout the cataract surgery process.

Conclusion First and second eye cataract surgery each independently increased participation in moderate leisuretime physical activity. This provides a rationale for timely first and second eye cataract surgery for bilateral cataract patients, even when they have relatively good vision.

\section{INTRODUCTION}

Physical activity is extremely important for health, well-being and quality of life. ${ }^{1}$ In Australia, physical inactivity was the fourth leading contributor to the burden of disease. ${ }^{2}$ Lack of sufficient physical activity can increase the risk of a wide range of diseases, such as cardiovascular disease, type 2 diabetes, cancer, and can also impact mental well-being. ${ }^{3}$ For older adults, physical activity may play an
Strengths and limitations of this study

Data was collected at three distinct time points: before first eye, after first eye and after second eye cataract surgery.

- The sample size of the study was relatively small.

- Recall bias related to physical activity participation was a possible limitation.

- Some potential confounding factors were not collected in this study.

important protective role against mild cognitive impairment, Alzheimer's disease and dementia. ${ }^{45}$ It can also benefit older adults by increasing muscle strength, balance ${ }^{6}$ and can prevent injurious falls. ${ }^{7}$

Cataract is a leading cause of visual impairment globally, accounting for $33 \%$ of visual impairment, ${ }^{8}$ with most adults aged over 70 years developing some degree of cataract. ${ }^{9}$ Fortunately, cataract surgery, which is the most commonly performed ophthalmic procedure globally, can remove cataract and correct for impaired vision. ${ }^{10}$

Since previous research has found that physical activity participation is related to visual function, ${ }^{11}{ }^{12}$ it is likely that cataract impacts on physical activity levels. Cataract frequently affects both eyes, meaning two surgeries are often required. It is currently unknown, however, whether physical activity levels change throughout the cataract surgery process and which types of physical activity are affected. Evidence has found that confidence levels may increase after cataract surgery due to improved vision, ${ }^{13}$ which could lead to some older adults undertaking more physical activity. However, during the waiting period between first and second eye cataract surgery there can be major differences in vision between the operated eye and unoperated eye, and for some patients vision may be equal or worse than before first eye surgery, ${ }^{14} 15$ negatively impacting on physical activity levels. 
To date, there are limited studies that have examined the separate impact of first and second eye cataract surgery on physical activity levels. Therefore, the research question for this study was: Does first eye and second eye cataract surgery increase the level of physical activity undertaken by older adults with bilateral cataract?

\section{METHODS}

This study is based on a subset of participants who were recruited as part of the Cataract Extraction and Driving Ability Research (CEDAR) Study. ${ }^{16}$ For the CEDAR Study, a total of 111 participants were recruited consecutively from three public hospitals in Western Australia (WA) and completed the first assessment. Previous papers have been published from this study based on the naturalistic driving data collected ${ }^{17-19}$; a falls diary component ${ }^{20}$ and further examinations of driving simulator performance are also planned. The current analysis of physical activity outcomes includes only 55 participants who completed the first, second and third assessments. This is the same subset of participants included in the study of fall outcomes ${ }^{20}$ but these results are based on data collected from a detailed questionnaire administered as part of the study.

\section{Study design}

A prospective cohort study of older adults aged $55+$ years with bilateral cataract, who were awaiting first eye cataract surgery in Perth, WA, was undertaken. The sample size of 55 participants was sufficient to detect a change in moderate leisure-time physical activity (increase or decrease) of $27 \mathrm{~min}$ (effect size of 0.45 ) at different stages of cataract surgery with $90 \%$ power at 0.05 significance. This was based on the Active Australia Survey population who had an average of $68 \mathrm{~min}$ (SD: 61) of moderate leisure-time physical activity per week. ${ }^{21}$

\section{Participants}

The recruitment of participants occurred consecutively through either a letter of invitation or a direct approach by an ophthalmologist in three public hospital eye clinics in WA between December 2014 and February 2017. Participants had to be at least 55 years of age and have a diagnosis of bilateral cataract. Those with other significant eye conditions (such as glaucoma, macular degeneration or diabetic retinopathy) were excluded from the study. Participants were also excluded if they were wheelchair-bound or diagnosed with one of the following conditions: dementia, Alzheimer's disease or Parkinson's disease, did not speak English, lived in a residential care facility or had previously undergone cataract surgery. All cataract surgeries were carried out one eye at a time using phacoemulsification.

\section{Patient involvement}

Patients were not involved in the design of the study or recruitment. Results of the study were disseminated to participants by mail.

\section{Data collection}

Data collection for this study involved researcher-administered questionnaires and three objective visual assessments. Data collection occurred at three time points: in the month before first eye cataract surgery, after first eye surgery and after second eye surgery. In this study, the three different stages of cataract surgery are referred to as 'before first eye surgery', 'after first eye surgery' and 'after second eye surgery'. Informed written consent was obtained from participants prior to collection of the data.

\section{Socio-demographic data}

Information on age, gender, marital status, country of birth, education level, living arrangements, self-reported medications, comorbid medical conditions and employment status were obtained from the researcher-administered questionnaire. The Mini-Mental State Examination ${ }^{22}$ (MMSE) of cognitive ability was also undertaken.

\section{Physical activity}

The Active Australia Survey ${ }^{21}$ was used to collect information on physical activity participation. Validity of this survey has been established for older adults. ${ }^{21}$ The questionnaire asked participants how many times and the total time (minutes) they spent on the following types of physical activity in the previous week: (1) walked continuously, for at least $10 \mathrm{~min}$, for recreation, exercise or to get to or from places, (2) vigorous gardening or heavy work around the yard, (3) vigorous leisure-time physical activity (eg, jogging, cycling, aerobics, competitive tennis) and (4) moderate leisure-time physical activity (eg, gentle swimming, social tennis, golf). Only collecting information on physical activity in the previous week minimised recall bias.

\section{Visual measures}

Three visual assessments were undertaken at each of the three time points in the study. These assessments were carried out under the guidance of an ophthalmologist under standard conditions, constant luminance and without mydriasis.

Monocular and binocular visual acuity measurements were obtained by using an Early Treatment Diabetic Retinopathy Study acuity chart, calibrated for a distance of 3 $\mathrm{m}$ and expressed as the logarithm of the minimum angle of resolution (logMAR). A lower logMAR score represented better visual acuity. Monocular and binocular contrast sensitivity measurements were obtained using the Mars Letter Contrast Sensitivity Test (Mars Perceptrix), calibrated at a distance of $50 \mathrm{~cm}$ and expressed as $\log$ units. Higher log units indicated better contrast sensitivity. Measurement of stereopsis was carried out using the Titmus Fly Stereotest (Stereo Optical Co., Inc.). Stereopsis was expressed as log seconds of arc, with a lower score indicating better stereopsis.

\section{Statistical analysis}

Descriptive statistics were used to describe the socio-demographic characteristics, visual measurements and 
physical activity levels during the last week for the cohort. Repeated measures analysis of variance was also used to analyse the changes in visual measurements and the four types of physical activity before first eye cataract surgery, after first eye surgery and after second eye surgery.

The main outcome of interest was change in the total minutes of moderate leisure-time physical activity as this was significant at the univariate level. Moderate leisuretime physical activity is defined as activity at a '... level that causes the heart to beat faster and some shortness of breath, but during which a person can still talk comfortably. ${ }^{23}$

A Generalised Estimating Equation (GEE) linear regression model was undertaken to analyse the change in the average weekly minutes of moderate leisure-time physical activity before first eye surgery, after first eye surgery and after second eye surgery, after accounting for relevant confounders. The after first eye surgery time point was used as the reference category in the model so that we could examine the change from before first eye surgery to after first eye surgery and from after first eye surgery to after second eye surgery. The GEE model also took account of the time between the three assessments. The above method is suitable for this type of longitudinal study design as the observations from each participant are not independent. ${ }^{24}$

Potential confounders included in the GEE model were: gender (women, men), age group (55-64, 65-74, $75+$ years), marital status (single/separated/divorced/ widowedvs married/de facto), comorbid medical conditions (yes, no), prescription medication (yes, no), employment status (unemployed/retired/on pension vs employed/self-employed), binocular visual acuity ( $\log$ MAR), binocular contrast sensitivity (log units) and stereopsis (log seconds of arc). Refractive management of visual impairment was not included as a confounding factor as all visual assessments were undertaken with habitual eyewear where applicable. Analyses were carried out using SAS software (V9.4; SAS Institute Inc., Cary, NC, USA). $\mathrm{P}$ values $<0.05$ were considered to be statistically significant.

This work was supported by Curtin University. The financial sponsors played no role in the design, execution, analysis and interpretation of data or writing of the study.

\section{RESULTS}

\section{Population demographics}

There were 55 participants in the study, who completed all three interviews and assessments, which provided a total of 165 observations. The socio-demographic characteristics of participants are outlined in table 1.

The mean age of participants before first eye cataract surgery was 73.3 years $(\mathrm{SD}=7.8)$ with a range from 56.1 to 87.8 years. Fifty-four per cent of participants were women $(\mathrm{n}=30), 61.8 \%$ were married/de facto $(\mathrm{n}=34), 54.6 \%$ did not live alone $(\mathrm{n}=30), 58.2 \%$ had higher than secondary education $(\mathrm{n}=32), 61.8 \%$ were not born in Australia
Table 1 Socio-demographic characteristics of study population before first eye surgery $(n=55)$

\begin{tabular}{|c|c|c|}
\hline Variables & $\mathbf{N}$ & $\%$ \\
\hline \multicolumn{3}{|l|}{ Gender } \\
\hline Women & 30 & 54.55 \\
\hline Men & 25 & 45.45 \\
\hline \multicolumn{3}{|l|}{ Age group (years) } \\
\hline $55-64$ & 10 & 18.18 \\
\hline $65-74$ & 21 & 38.18 \\
\hline $75+$ & 24 & 43.64 \\
\hline \multicolumn{3}{|l|}{ Marital status } \\
\hline Single, separated, divorced, widowed & 21 & 38.18 \\
\hline Married, de facto & 34 & 61.82 \\
\hline \multicolumn{3}{|l|}{ Living arrangements } \\
\hline Alone & 25 & 45.45 \\
\hline Not alone & 30 & 54.55 \\
\hline \multicolumn{3}{|l|}{ Education level } \\
\hline Primary or secondary school & 23 & 41.82 \\
\hline Higher education & 32 & 58.18 \\
\hline \multicolumn{3}{|l|}{ Country of birth } \\
\hline Not Australia & 34 & 61.82 \\
\hline Australia & 21 & 38.18 \\
\hline \multicolumn{3}{|l|}{ Prescription medication } \\
\hline No & 7 & 12.73 \\
\hline Yes & 48 & 87.27 \\
\hline \multicolumn{3}{|l|}{ Comorbid medical conditions } \\
\hline No & 1 & 0 \\
\hline Yes & 54 & 98.18 \\
\hline \multicolumn{3}{|l|}{ Employed } \\
\hline Yes & 10 & 18.18 \\
\hline No & 45 & 81.82 \\
\hline
\end{tabular}

$(\mathrm{n}=34), 87.3 \%$ were on at least one prescription medication $(\mathrm{n}=48), 98.2 \%$ had at least one comorbid medical condition $(n=54)$ and $61.8 \%$ were retired $(n=34)$. At baseline, the mean Mini Mental State Examination score was $27.6(\mathrm{SD}=2.2)$.

The waiting time between first and second eye cataract surgery ranged between 9 and 417 days with a mean of 99.6 days $(\mathrm{SD}=73.7)$. The second assessment (after first eye surgery) occurred on average 59.7 days after surgery ( $\mathrm{SD}=41.3)$ with a range of 9-254 days. The third assessment (after second eye surgery) occurred between 28 and 238 days, with an average of 111.4 days after second eye surgery $(\mathrm{SD}=40.2)$.

\section{Visual measures}

Visual measures during the three stages of cataract surgery are presented in table 2. Mean binocular visual acuity significantly improved from $0.15 \quad(\mathrm{SD}=0.15)$ $\log$ MAR at baseline to 0.08 ( $\mathrm{SD}=0.21) \log$ MAR after first 
Table 2 Visual measurements for participants before first eye cataract surgery, after first eye surgery and after second eye surgery $(n=55)$

\begin{tabular}{|c|c|c|c|c|}
\hline & $\begin{array}{l}\text { Before first eye } \\
\text { surgery }\end{array}$ & After first eye surgery & $\begin{array}{l}\text { After second eye } \\
\text { surgery }\end{array}$ & \\
\hline Variable & Mean (SD) & Mean (SD) & Mean (SD) & P value \\
\hline \multicolumn{5}{|c|}{ Visual acuity (logMAR) } \\
\hline Better eye & $0.18(0.15)$ & $0.10(0.22)$ & $0.00(0.19)$ & $<0.0001$ \\
\hline Worse eye & $0.39(0.24)$ & $0.36(0.26)$ & $0.11(0.19)$ & $<0.0001$ \\
\hline Binocular & $0.15(0.15)$ & $0.08(0.21)$ & $-0.02(0.19)$ & $<0.0001$ \\
\hline \multicolumn{5}{|c|}{ Contrast sensitivity (log units) } \\
\hline Better eye & $1.57(0.14)$ & $1.62(0.28)$ & $1.68(0.11)$ & $<0.001$ \\
\hline Worse eye & $1.41(0.29)$ & $1.47(0.27)$ & $1.61(0.13)$ & $<0.0001$ \\
\hline Binocular & $1.64(0.14)$ & $1.67(0.25)$ & $1.75(0.08)$ & $<0.001$ \\
\hline \multicolumn{5}{|c|}{ Stereopsis (log seconds of arc) } \\
\hline Binocular & $2.14(0.64)$ & $2.31(0.72)$ & $1.96(0.60)$ & 0.002 \\
\hline
\end{tabular}

eye surgery, and then to $-0.02(\mathrm{SD}=0.19) \log \mathrm{MAR}$ after second eye surgery $(\mathrm{p}<0.001)$. Binocular contrast sensitivity also significantly improved from $1.64(\mathrm{SD}=0.14) \log$ units at baseline, to $1.67(\mathrm{SD}=0.25) \log$ units after first eye surgery and to $1.75(\mathrm{SD}=0.08) \log$ units after second eye cataract surgery $(\mathrm{p}<0.001)$. Stereopsis significantly worsened from $2.14(\mathrm{SD}=0.64) \log$ seconds of arc to 2.31 $(\mathrm{SD}=0.72)$ after first eye surgery, and then improved to $1.96(\mathrm{SD}=0.6) \log$ seconds of arc after second eye surgery $(\mathrm{p}=0.002)$.

Average weekly levels of physical activity

Table 3 presents the average weekly levels of four types of physical activity (walking, gardening, vigorous leisuretime physical activity and moderate leisure-time physical activity). For walking, gardening and vigorous physical activity, average minutes per week decreased after first eye surgery and increased again after second eye surgery; however, these changes were not statistically significant $(p>0.05)$. Average minutes of moderate leisuretime physical activity per week, however, significantly increased from 27 ( $\mathrm{SD}=92.3)$ min before first eye surgery, to $35(\mathrm{SD}=101.0)$ min after first eye surgery and to 61 $(\mathrm{SD}=151.3)$ min after second eye surgery $(\mathrm{p}=0.01)$.
Multivariate analysis-moderate leisure-time physical activity

Table 4 presents the results of the GEE linear regression model examining change in moderate leisure-time physical activity through the cataract surgery process. The model found that participants spent significantly less time per week (20 min) on moderate leisure-time physical activity before first eye cataract surgery compared with after first eye surgery $(\mathrm{p}=0.04)$ after accounting for all confounders. After second eye cataract surgery, participants spent significantly more time per week $(32 \mathrm{~min})$ on moderate physical activity compared with after first eye surgery $(\mathrm{p}=0.02)$. Therefore, time spent participating in moderate leisure-time physical activity significantly increased from before first eye to after first eye surgery and significantly increased again from after first eye surgery to after second eye surgery. Finally, those who took at least one prescription medication spent $49 \mathrm{~min}$ less time on moderate leisure-time physical activity per week $(\mathrm{p}=0.01)$.

\section{DISCUSSION}

This study found that participation in moderate leisure-time physical activity significantly increased by

Table 3 Average weekly physical activity participation for participants before first eye cataract surgery, after first eye surgery and after second eye surgery $(n=55)$

\begin{tabular}{|c|c|c|c|c|c|c|c|c|c|c|}
\hline & \multicolumn{3}{|c|}{ Before first eye surgery } & \multicolumn{3}{|c|}{ After first eye surgery } & \multicolumn{3}{|c|}{ After second eye surgery } & \multirow[b]{2}{*}{$P$ value } \\
\hline & $\begin{array}{l}\text { Minutes } \\
\text { (previous } \\
\text { week) }\end{array}$ & SD & $\%$ & $\begin{array}{l}\text { Minutes } \\
\text { (previous } \\
\text { week) }\end{array}$ & SD & $\%$ & $\begin{array}{l}\text { Minutes } \\
\text { (previous } \\
\text { week) }\end{array}$ & SD & $\%$ & \\
\hline Walking & 246.3 & 586.8 & 56.6 & 159.5 & 270.6 & 55.7 & 202.5 & 394.4 & 45.7 & 0.52 \\
\hline Gardening & 125.2 & 273.4 & 28.8 & 79.0 & 161.2 & 27.6 & 142 & 229.7 & 32.0 & 0.24 \\
\hline $\begin{array}{l}\text { Vigorous } \\
\text { physical activity }\end{array}$ & 36.3 & 109.0 & 8.3 & 12.7 & 36.4 & 4.4 & 36.8 & 110.9 & 8.3 & 0.07 \\
\hline $\begin{array}{l}\text { Moderate } \\
\text { physical activity }\end{array}$ & 27.4 & 92.3 & 6.3 & 35.0 & 101.0 & 12.2 & 61.4 & 153.3 & 13.9 & 0.01 \\
\hline
\end{tabular}


Table 4 Generalised Estimating Equation model for the impact of first and second eye cataract surgery on total minutes of moderate physical activity $(n=55)^{\star}$

\begin{tabular}{|c|c|c|c|c|}
\hline Variable & $\begin{array}{l}\text { Parameter } \\
\text { estimate }\end{array}$ & $\begin{array}{l}95 \% \\
\text { Confide } \\
\text { limits }\end{array}$ & nce & P Value \\
\hline \multicolumn{5}{|l|}{ Cataract surgery } \\
\hline $\begin{array}{l}\text { After first eye } \\
\text { surgery }\end{array}$ & 1.00 & & & \\
\hline $\begin{array}{l}\text { Before first eye } \\
\text { surgery }\end{array}$ & -20.39 & -40.08 & -0.71 & $0.04 \dagger$ \\
\hline $\begin{array}{l}\text { After second eye } \\
\text { surgery }\end{array}$ & 32.17 & 5.07 & 59.27 & $0.02 \dagger$ \\
\hline \multicolumn{5}{|c|}{ Prescription medication } \\
\hline No & 1.00 & & & \\
\hline Yes & -49.22 & -83.83 & -14.61 & $0.01 \dagger$ \\
\hline
\end{tabular}

*Adjusted for gender, age group, marital status, employment status, comorbidities, binocular visual acuity, binocular contrast sensitivity and stereopsis, which were not significant ( $p>0.05)$. $\dagger$ Significant at $p \leq 0.05$.

approximately $20 \mathrm{~min} /$ week after first eye cataract surgery and by a further $30 \mathrm{~min} /$ week after second eye surgery. This suggests that both first and second eye surgery have separate positive effects on increasing or restoring participation in moderate physical activity for bilateral cataract patients. This is a positive finding since the physical activity recommendations for older Australians state that older people should accumulate 30 min of moderate intensity physical activity on most, preferably all, days in order to achieve health and well-being benefits. ${ }^{23}$

Moderate physical activity (eg, gentle swimming, social tennis, golf) by definition, is likely to be deliberate, planned, may require good vision and also transport to a location. ${ }^{25}$ Previous research has found that visual impairment is associated with significantly decreased physical activity. ${ }^{26}{ }^{27}$ For participants in this study, it is likely that visual impairment from cataract resulted in reduced participation in moderate physical activity while awaiting surgery. Then participation in moderate physical activity increased or was restored as vision improved through first and second eye cataract surgery.

Interestingly, other physical activity including walking, gardening and vigorous physical activity appeared to decrease following first eye surgery, although this change was not significant possibly due to the small sample size. Activities like gardening and walking are more incidental $^{25}$ and may not require a high level of vision like moderate physical activity and this may explain why they did not significantly change as a result of cataract surgery. Vigorous physical activity is similar in nature to moderate activity but only a small number of cataract patients in this study reported participating, so this is likely why no significant change was found. The impact of cataract surgery on these other activities should be investigated further however, since the possible decrease in these activities after first eye surgery would support the need to operate on the second eye as soon as possible for bilateral cataract patients.

This study highlighted the importance of second eye cataract surgery, as well as first eye surgery for increasing/ restoring participation in moderate physical activity. While it is known that first eye surgery brings about larger improvements in bilateral vision than second eye surgery, some patients experience major differences in vision between the operated eye and unoperated eye after first eye surgery. ${ }^{14}{ }^{15}$ Since second eye surgery corrects these differences, this may explain the important significant increase in moderate physical activity following second eye surgery. However, while recovery from cataract surgery is usually rapid (within a few days), it is possible that those who had first and second eye surgery in short succession had not fully recovered by their second assessment. In addition, the average time to assessment after second eye surgery was longer than after first eye surgery. These factors may have contributed to the smaller increase in moderate physical activity following first eye surgery compared with the larger increase after second eye surgery. It should also be noted that this cohort of cataract patients had relatively good baseline vision compared with previous studies examining outcomes of cataract surgery. ${ }^{13-15}$ Therefore, the findings suggest that cataract surgery has positive benefits for physical activity participation, even among patients with relatively good vision. This should be further investigated with a larger sample and in other countries to determine whether the findings are generalisable.

Strengths of this study include the three distinct time points in which data was collected. However, the sample size of the study was relatively small, with 55 participants providing 165 observations. This may not have been a large enough sample to detect all associations. Furthermore, socioeconomic status, overweight and obesity, diet and smoking have been shown to be associated with physical activity, ${ }^{28}$ but were not included in our study. Recall bias was another possible limitation as participants were asked to recall the total minutes spent on physical activity in the previous week. Future studies should consider implementing a diary or objective measures such as accelerometers $^{29}$ to more accurately record participation in physical activity.

In conclusion, this study found that first and second eye cataract surgery each independently increased/ restored participation in moderate leisure-time physical activity. Since physical activity is associated with quality of life and reduced morbidity and mortality, ${ }^{13}$ this provides a rationale for timely first and second eye cataract surgery for bilateral cataract patients, even when they have relatively good baseline vision.

Contributors LBM led the design of the study, collected the data, conducted the data analysis, interpretation of data and drafted the manuscript. YRF conducted the data analysis and drafted the manuscript. MF made substantial contributions to the conception and design of the study, interpreted the data and was involved in drafting and revising the manuscript. KB contributed the analysis of data and 
drafting and revising the manuscript. $\mathrm{KC}$ contributed to the design of the study, analysis of data and drafting and revising of the manuscript.

Funding This work was supported by Curtin University. The financial sponsors played no role in the design, execution, analysis and interpretation of data or writing of the study.

Competing interests None declared.

Patient consent for publication Not required.

Ethics approval Ethics approval was obtained from all participating hospitals and from the Curtin University Human Research Ethics Committee.

Provenance and peer review Not commissioned; externally peer reviewed. Data sharing statement There are no additional unpublished data available. Open access This is an open access article distributed in accordance with the Creative Commons Attribution Non Commercial (CC BY-NC 4.0) license, which permits others to distribute, remix, adapt, build upon this work non-commercially, and license their derivative works on different terms, provided the original work is properly cited, appropriate credit is given, any changes made indicated, and the use is non-commercial. See: http://creativecommons.org/licenses/by-nc/4.0/.

\section{REFERENCES}

1. Anokye NK, Trueman P, Green C, et al. Physical activity and health related quality of life. BMC Public Health 2012;12:624.

2. Australian Institute of Health and Welfare (AIHW). Australian Burden of Disease Study: impact and causes of illness and death in Australia 2011. Australian Burden of Disease Study series no. 3. Canberra: AlHW, 2016.

3. Warburton DE, Nicol CW, Bredin SS. Health benefits of physical activity: the evidence. CMAJ 2006;174:801-9.

4. Geda YE, Roberts RO, Knopman DS, et al. Physical exercise, aging, and mild cognitive impairment: a population-based study. Arch Neurol 2010;67:80-6.

5. Gomez-Pinilla F, Hillman C. The influence of exercise on cognitive abilities. Compr Physiol 2013;3:403-28.

6. Cho SI, An DH. Effects of a fall prevention exercise program on muscle strength and balance of the old-old elderly. J Phys Ther Sci 2014;26:1771-4.

7. El-Khoury F, Cassou B, Charles MA, et al. The effect of fall prevention exercise programmes on fall induced injuries in community dwelling older adults: systematic review and meta-analysis of randomised controlled trials. BMJ 2013;347:347.

8. World Health Organization. Visual impairment and blindness. 2014. http://www.who.int/mediacentre/factsheets/fs282/en/ (Accessed 22 May 2018).

9. Meuleners LB, Fraser ML, $\mathrm{Ng}$ J, et al. The impact of first- and second-eye cataract surgery on injurious falls that require hospitalisation: a whole-population study. Age Ageing 2014;43:341-6.

10. Gothwal VK, Wright TA, Lamoureux EL, et al. Improvements in visual ability with first-eye, second-eye, and bilateral cataract surgery measured with the visual symptoms and quality of life questionnaire. J Cataract Refract Surg 2011;37:1208-16.
11. Paunksnis A, Kusleika S, Kusleikaite M. The relationship of the intensity of lens opacity with physical activity. Medicina 2006;42:738-43.

12. Swanson MW, Bodner E, Sawyer P, et al. Visual acuity's association with levels of leisure-time physical activity in community-dwelling older adults. J Aging Phys Act 2012;20:1-14.

13. Harwood RH, Foss AJ, Osborn F, et al. Falls and health status in elderly women following first eye cataract surgery: a randomised controlled trial. Br J Ophthalmol 2005;89:53-9.

14. Castells $\mathrm{X}$, Comas $\mathrm{M}$, Alonso J, et al. In a randomized controlled trial, cataract surgery in both eyes increased benefits compared to surgery in one eye only. J Clin Epidemiol 2006;59:201-7.

15. Comas $M$, Castells $X$, Acosta ER, et al. Impact of differences between eyes on binocular measures of vision in patients with cataracts. Eye 2007;21:702-7.

16. Meuleners LB, Agramunt $\mathrm{S}, \mathrm{Ng} J \mathrm{JQ}$, et al. The cataract extraction and driving ability research study protocol: Characterisation of deficits in driving performance and self-regulation among older drivers with bilateral cataract. Inj Prev 2015;21:424-9.

17. Agramunt S, Meuleners L, Chow KC, et al. A validation study comparing self-reported travel diaries and objective data obtained from in-vehicle monitoring devices in older drivers with bilateral cataract. Accid Anal Prev 2017;106:492-7.

18. Agramunt S, Meuleners LB, Fraser ML, et al. First and second eye cataract surgery and driver self-regulation among older drivers with bilateral cataract: a prospective cohort study. BMC Geriatr 2018;18:51

19. Agramunt S, Meuleners LB, Fraser ML, et al. Do older drivers with bilateral cataract self-regulate their driving while waiting for first eye cataract surgery? Clin Interv Aging 2017;12:1911-20.

20. Feng YR, Meuleners LB, Fraser ML, et al. The impact of first and second eye cataract surgeries on falls: a prospective cohort study. Clin Interv Aging 2018;13:1457-64.

21. Heesch KC, Hill RL, van Uffelen JG, et al. Are Active Australia physical activity questions valid for older adults? J Sci Med Sport 2011;14:233-7.

22. Folstein MF, Folstein SE, McHugh PR. "Mini-mental state". A practical method for grading the cognitive state of patients for the clinician. J Psychiatr Res 1975;12:189-98.

23. Sims J, Hill K, Hunt S, et al. Physical activity recommendations for older Australians. Australas J Ageing 2010;29:81-7.

24. LIANG K-YEE, Zeger SL. Longitudinal data analysis using generalized linear models. Biometrika 1986;73:13-22.

25. Rebar AL, Maher JP, Doerksen SE, et al. Intention-behavior gap is wider for walking and moderate physical activity than for vigorous physical activity in university students. J Sci Med Sport 2016;19:130-4.

26. van Landingham SW, Willis JR, Vitale S, et al. Visual field loss and accelerometer-measured physical activity in the United States. Ophthalmology 2012;119:2486-92.

27. Willis JR, Jefferys JL, Vitale S, et al. Visual impairment, uncorrected refractive error, and accelerometer-defined physical activity in the United States. Arch Ophthalmol 2012;130:329-35.

28. Trost SG, Owen N, Bauman AE, et al. Correlates of adults participation in physical activity: review and update. Med Sci Sports Exerc 2002;34:1996-2001.

29. Sengupta S, Nguyen AM, van Landingham SW, et al. Evaluation of real-world mobility in age-related macular degeneration. BMC Ophthalmol 2015;15:9. 